\title{
A new species of Ammothella (Pycnogonida: Ammotheidae) from deep water off San Nicolas Island, California*
}

\author{
Masahiro Dojiri ${ }^{1}$, Donald B. Cadien ${ }^{2}$ \& Charles A. Phillips ${ }^{1}$ \\ ${ }^{1}$ Biology Laboratory, Hyperion Treatment Plant, 12000 Vista del Mar, Playa del Rey, CA 90293, \\ U.S.A.; ${ }^{2}$ Marine Biology Laboratory, Los Angeles County Sanitation Districts, 24501 S. Figueroa, \\ Carson, $C A$ 90745, U.S.A.
}

Keywords: Pycnogonida, Ammotheidae, Ammothella, San Nicolas Island, Channel Islands, southern California

\begin{abstract}
Ammothella killix $\mathrm{n}$. sp. is described from upper bathyal depths on the Cortez Ridge; it is the tenth in the genus from the eastern Pacific, and sixth from California. It differs from its congeners most noticeably in having chelifore fusion, and in bearing slender spiny tubercles on all of the following parts: the chelifore scapes, ocular tubercle, abdomen, lateral processes, first coxae, mid-dorsal surface, and anterior cephalic corners. A key to the species of adult Ammothella from California waters is included.
\end{abstract}

\section{Résumé}

On décrit Ammothella killix n. sp. des niveaux supérieurs du bathyal dans la zone du Cortez Range; il s'agit de la dixième espèce du genre pour le Pacifique Est et de la sixième pour la Californie. Elle diffère des congénères surtout par la fusion des chélifores et par la présence de minces tubercules épineux sur les scapes du chélifore, les tubercules oculaires, l'abdomen, les processus latéraux, les coxae antérieures, la surface médiodorsale, et les angles céphaliques antérieurs. Une clé pour les adultes des espèces d'Ammothella des eaux de la Californie est présentée.

\section{Introduction}

When first encountered during examination of the pycnogonid collections of the Los Angeles County Museum of Natural History, the specimens described below were viewed as a new species of Nymphopsis because the slender body and legs bore spiny tubercles. Although Fry (1978: 51) placed
Nymphopsis and the closely related trio of $\mathrm{Am}$ mothella, Cilunculus, and Scipiolus in different superfamilies on the basis of a numerical analysis, subsequent authors, awaiting cladistic analysis before scrapping traditional usage, have not adopted his classification. At present, they are all viewed as ammotheids. Their differentiation remains difficult in practice, and addition of new species continues to erode generic boundaries.

The tall spinose tibial tubercles of Nymphopsis serve to distinguish it from the other three, but occurrence of spinose tubercles on other areas of the body in the new species suggest the possibility of intergradation as more species are added to the two genera, Nymphopsis and Ammothella. Hedgpeth's assertion (1948: 240-241) that species of $\mathrm{Nym}$ phopsis have the second segment of the scape clavate or flared ("trumpet shaped"), while species of Ammothella lack this feature, is no longer supportable. Many species, lacking the spiny tibial tubercles of Nymphopsis and usually assigned to Ammothella, have the second segment of the scape clavate. Presence of modified compound oviger spines in the male, although occurring in Ammothella, was suggested as more typical of Nymphopsis by Stock (1978: 196).

The distinctness of Ammothella and Cilunculus has been repeatedly questioned (e.g. Hedgpeth, 1949; Stock, 1978; Child, 1982a; and Arnaud \& Child, 1988) and two species formerly placed in

\footnotetext{
* Contribution No. 3 of the Southern California Association of Marine Invertebrate Taxonomists.
} 
Ammothella have since been transferred to Cilunculus. Characters separating these genera are the cephalic hood of Cilunculus, lengths of oviger segments (second segment $>$ fourth segment in Cilunculus, and second segment $\leq$ fourth segment in Ammothella) (Nakamura \& Child, 1983: 5), structure of the cement gland in the male, and relative length of the ovigers (Stock, 1978: 197).

Although overlapping one or more of the above genera in several characters, Scipiolus is distinguished from them by lack of a propodial heel.

A complete revision to clearly define the ammotheid genera is badly needed. We have not attempted it here, opting instead to assign our species to the genus in which it best fits according to current practice.

\section{Materials and methods}

Specimens were cleared in $85 \%$ lactic acid for at least 24 hours and dissected on wooden slides (Humes \& Gooding, 1964). Measurements were made with an ocular micrometer, and illustrations were drawn with the aid of a drawing tube attached to a Nikon Optiphot, HFX-II. Descriptions are based on dissected female and male paratypes. Type-specimens have been deposited in the Division of Life Sciences, Natural History Museum of Los Angeles County (LACM), 900 Exposition Blvd., Los Angeles, CA 90007, USA.

\section{Description}

\section{Family AMMOTHEIDAE}

Ammothella killix n. sp. (Figs. 1-5)

Material examined. - One $\$$ holotype (LACM 77-132.1), $1 \sigma^{\circ}$ allotype (LACM 77-132.2), and 6 paratypes ( 2 adult $९$ \&, 1 juvenile $\$$ with functional chelae, and 3 adult $\sigma \sigma$; LACM 77-132.3) from mixed cobble and gravel at 366-372 m, R.V. "Velero IV" (cruise no. 1383), sta. 25767, off Cortez Ridge, San Nicolas Island (Channel Islands), California, $33^{\circ} 58.45^{\prime} \mathrm{N}$, $119^{\circ} 32.2^{\prime} \mathrm{W}$ (mid-point of transect), collected with $3 \mathrm{ft}$ rock dredge on 14 February 1977; $1 \odot$ and $1 \sigma$ dissected for detailed examination, and subsequently preserved in $70 \%$ ethanol in microvials.

Female. - Trunk (Figs. 1A, B) oval in outline, distinctly segmented between trunk segments 1 and 2 , and segments 2 and 3; trunk segments 3 and 4 completely fused; first-third trunk segments each with 1 long, spiny tubercle on mid-dorsal surface; second and third trunk segments also may have dorsolateral tubercles (these absent in other specimens examined). Lateral processes (crurigers) separated by slightly more than their diameters, and bearing 1-5 spiny tubercles (see Figs. 1A, B). Cephalic segment with hornlike, spiny tubercles on each anterior corner. Ocular tubercle (Fig. 1B) long, about 6 or 7 times as long as median diameter, with 4 lateral spiny tubercles ( 1 adult female paratype with only 1 lateral tubercle, holotype with none); eyes absent. Proboscis pyriform (formula $\mathbf{B}^{\prime}: 1$ in the descriptive system of Fry \& Hedgpeth, 1969), about as long as trunk. Abdomen long, extending greatly beyond distalmost extension of first coxa of leg 4, carrying numerous mid-dorsal and dorsolateral spiny tubercles (8 in Fig. 1), and bearing 4 subterminal setae. Measurements of holotype and female paratype are provided (Table I).

Chelifore scape 2-segmented. Basal segment (Fig. 1A) fused to its counterpart along proximal medial surface, and armed with 2-3 spiny tubercles and 1 distal spine. Second segment of scape (Figs. $1 C, D)$ nearly twice length of first, and equipped with several (6-7) spiny tubercles and 9 spines. Chela (Fig. 1E) small, almost 2 times longer than wide, armed with 1 dorsolateral spine and 2 conical membranous tubercles which probably represent remnants of finger. Each spine with barbs on distal half.

Chelifore of juvenile female (Figs. 1F, G) with scape similar to that in adult, except tubercles not spiny and spines not barbed. Fixed and movable fingers of chela curved, overlapping, and each carrying several (3-4) teeth along inner margin.

Palp (Figs. 2A, B) 9-segmented. First segment short, robust, and unarmed. Second segment almost twice length of fourth segment. Third and fifth segments short, similar in length and width. Sixth-ninth segments progressively shorter. Armature formula for illustrated paratype as follows (Roman numerals representing spines, Arabic numerals setae), $\mathrm{L}$ (left)/R (right): $0 / 0,1 / 0,2 / 1$, $5+\mathrm{IV} / 5+\mathrm{IV}, 10 / 10,10 / 11,6 / 5,5 / 5,7 / 7$.

Oviger (Figs. 2C-E) 10-segmented. First seg- 


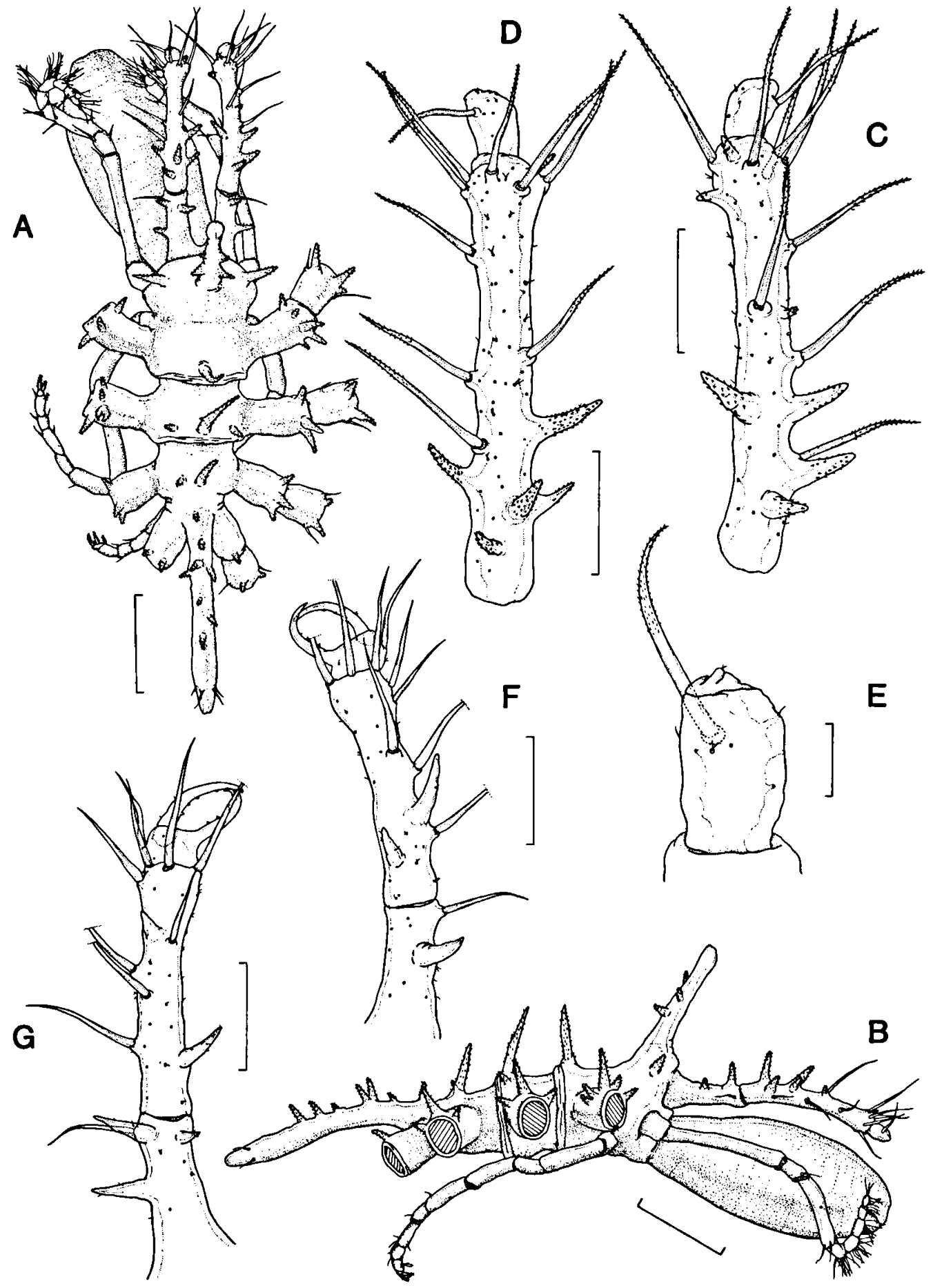

Fig. 1. Ammothella killix n. sp., \& paratype: A, trunk, dorsal; B, trunk, lateral; C, terminal segments of right chelifore, dorsal; D, terminal segments of left chelifore, dorsal; E, tip of right chelifore, ventral; F, right chelifore of juvenile $\$$, dorsal; G, left chelifore of juvenile $Q$, dorsal. Scales: $0.5 \mathrm{~mm}$ in A, B; $0.2 \mathrm{~mm}$ in C, D, F, G; $0.05 \mathrm{~mm}$ in E. 


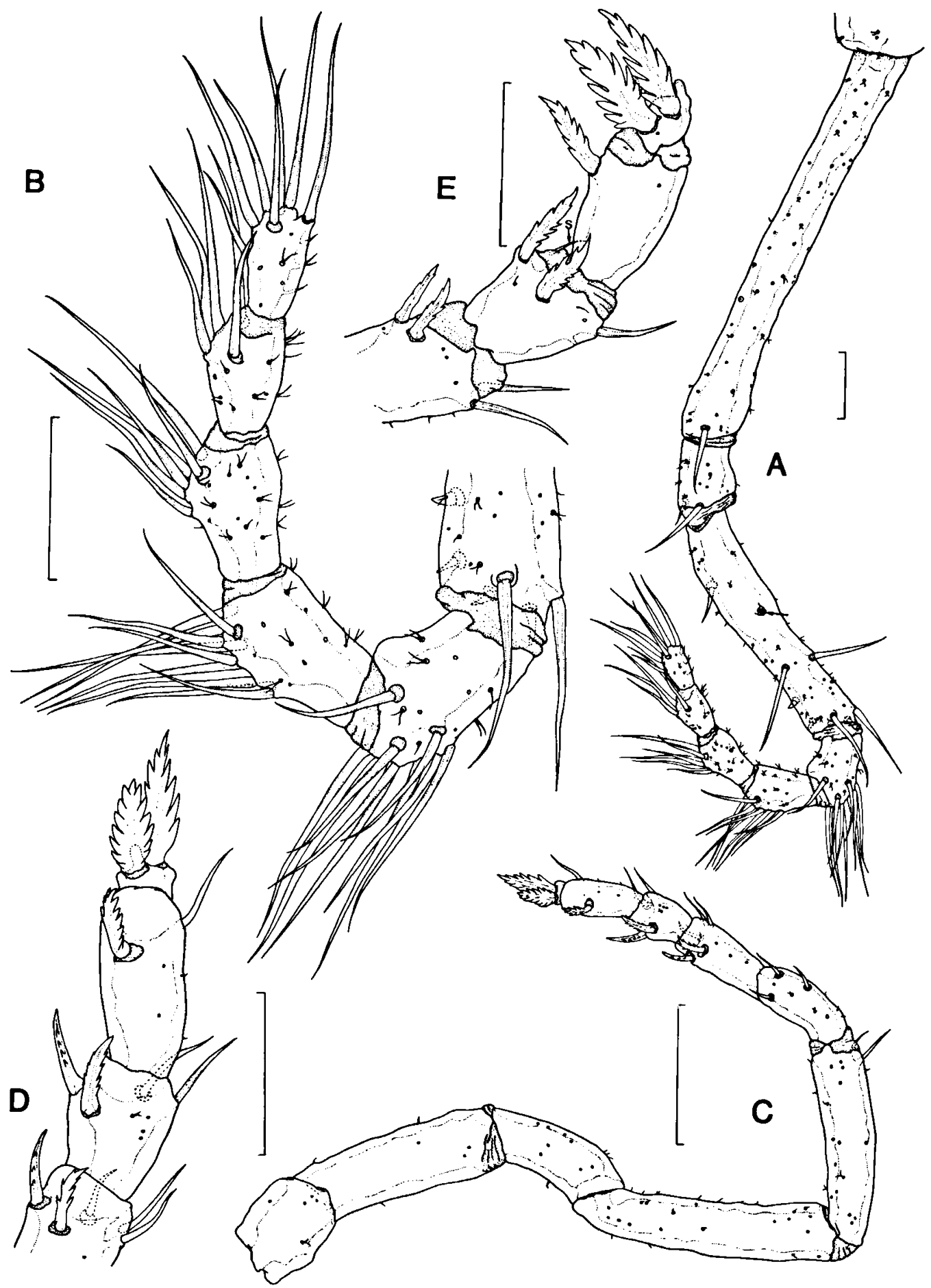

Fig. 2. Ammothella killix n. sp., ९ paratype: A, palp, lateral (small arrow represents missing seta); B, distal portion of palp, lateral; C, oviger, ventral; D, terminal segments of left oviger, ventral; $E$, terminal segments of right oviger, lateral (s = setule). Scales: 0.1 $\mathrm{mm}$ in $\mathrm{A}, \mathrm{B}, \mathrm{D}, \mathrm{E} ; \mathbf{0 . 2} \mathrm{mm}$ in $\mathrm{C}$. 


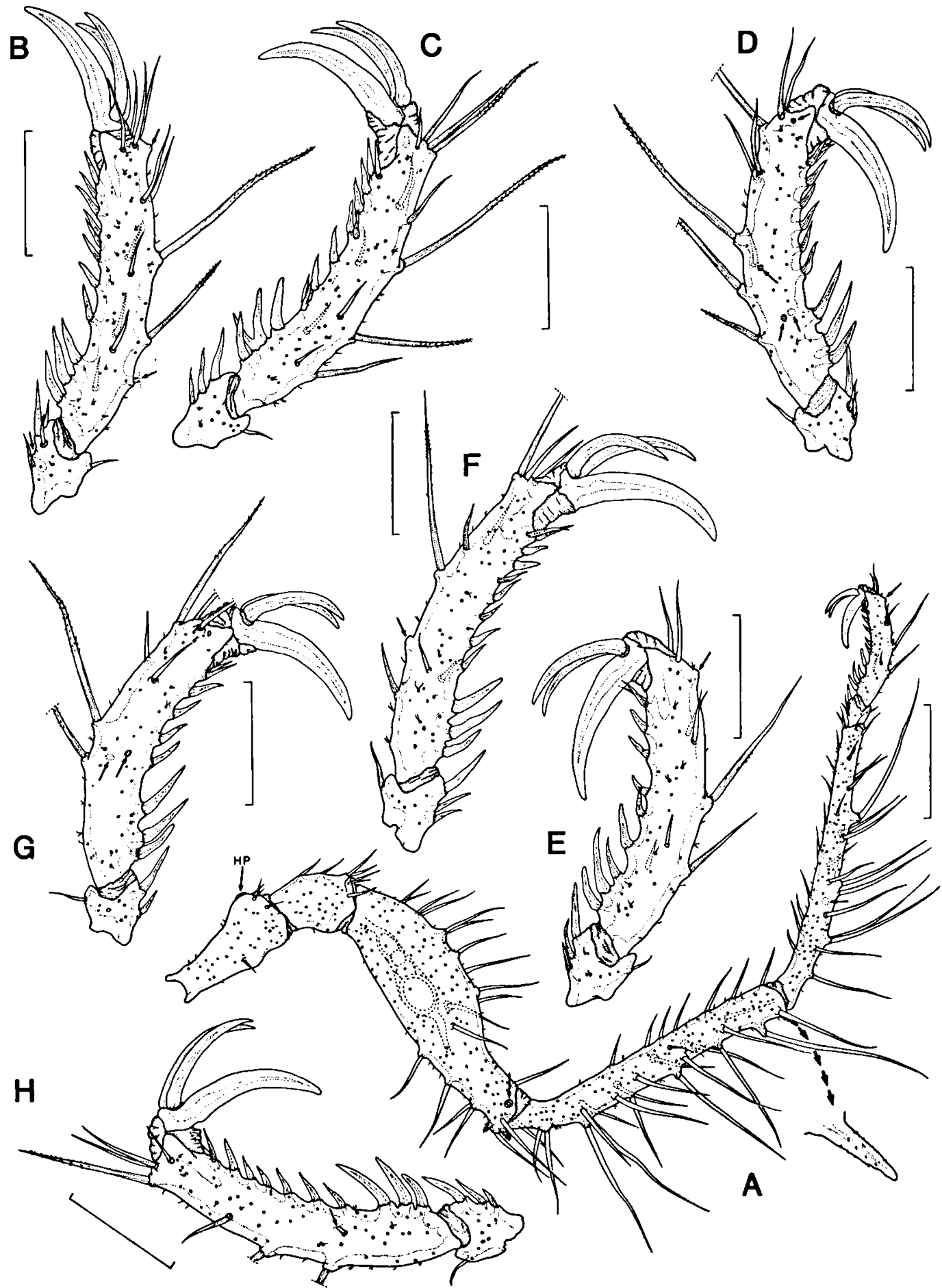

Fig. 3. Ammothella killix n. sp., \& paratype: A, third leg, anterior (HP = hyaline pad with genital pore); B, terminal segments of right first leg, anterior; C, terminal segments of right second leg, anterior; D, terminal segments of left second leg, anterior; E, terminal segments of right third leg, anterior; F, terminal segments of left third leg, anterior; $G$, terminal segments of left fourth leg, anterior; $H$, terminal segments of right fourth leg, anterior. Scales: $0.5 \mathrm{~mm}$ in A; $0.2 \mathrm{~mm}$ in B-H. Small arrows represent missing spines. 


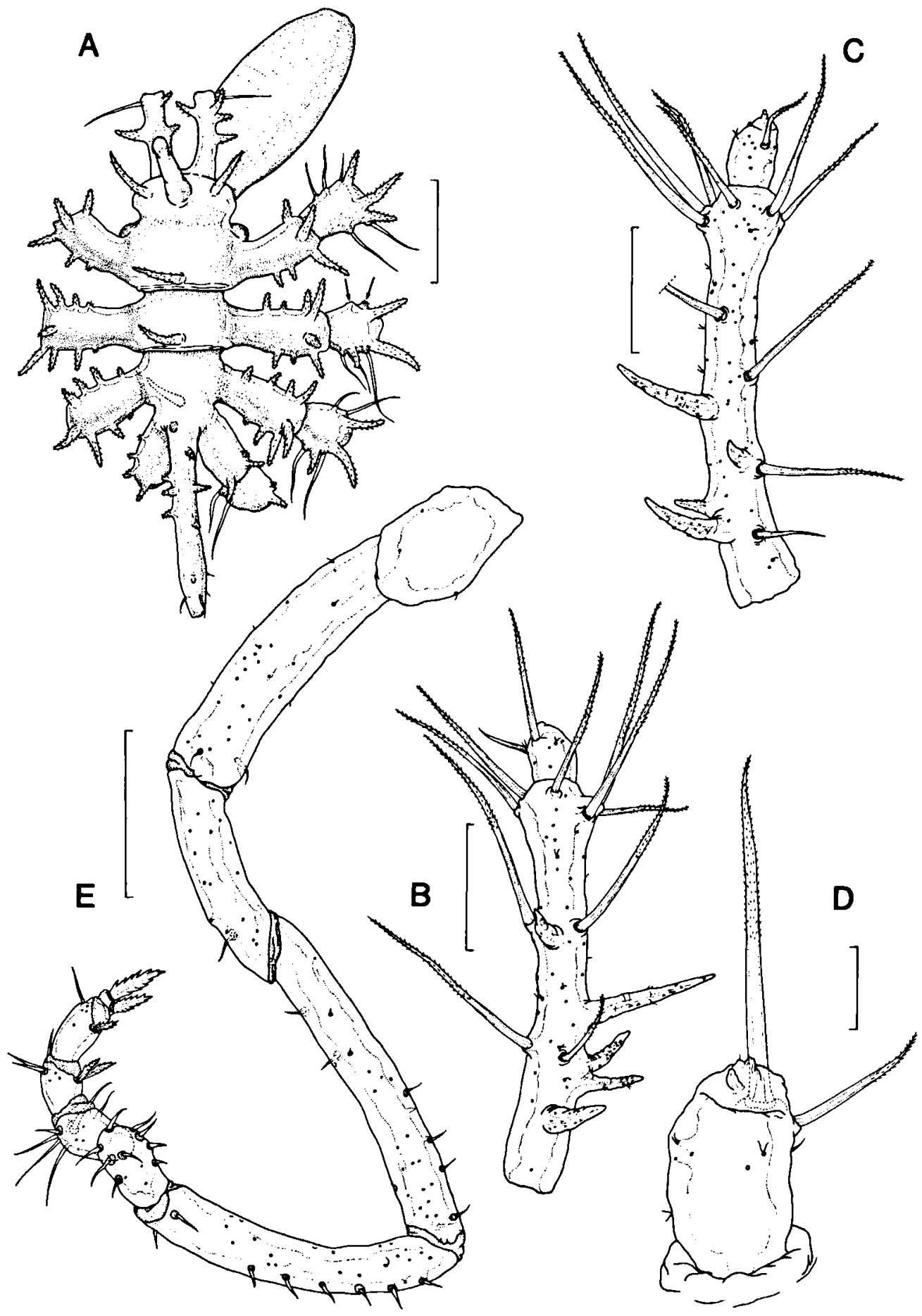

Fig. 4. Ammothella killix n. sp., o paratype: A, trunk, dorsal; B, terminal segments of right chelifore, dorsal; C, terminal segments of left chelifore, dorsal; D, tip of right chelifore, ventral; E, oviger, ventral. Scales: $0.5 \mathrm{~mm}$ in A; $0.2 \mathrm{~mm}$ in B, C; $0.05 \mathrm{~mm}$ in D; 0.3 $\mathrm{mm}$ in $\mathbf{E}$. 
Table I. Measurements (in $\mathrm{mm}$ ) of Ammothella killix $\mathrm{n} . \mathrm{sp}$.

\begin{tabular}{|c|c|c|c|c|}
\hline & Holotype & Paratype 9 & Allotype $\sigma$ & Paratype $\sigma^{\circ}$ \\
\hline Trunk length* & 1.85 & 1.59 & 1.49 & 1.52 \\
\hline Trunk width** & 1.47 & 1.21 & 1.27 & 1.34 \\
\hline Proboscis length & 1.70 & 1.29 & 1.21 & 1.34 \\
\hline Ocular tubercle length & 0.53 & 0.51 & 0.40 & 0.51 \\
\hline Abdomen length & 1.21 & 1.01 & 0.94 & 0.91 \\
\hline \multicolumn{5}{|l|}{ Third leg: } \\
\hline Coxa 1 & 0.23 & 0.22 & 0.28 & 0.29 \\
\hline Coxa 2 & 0.58 & 0.63 & 0.66 & 0.66 \\
\hline Coxa 3 & 0.43 & 0.41 & 0.35 & 0.31 \\
\hline Femur & 1.24 & 1.16 & 1.11 & 1.09 \\
\hline Tibia I & 1.31 & 1.19 & 1.11 & 1.19 \\
\hline Tibia 2 & 1.16 & 1.19 & 1.01 & 1.19 \\
\hline Tarsus & 0.17 & 0.14 & 0.14 & 0.09 \\
\hline Propodus & 0.61 & 0.49 & 0.58 & 0.51 \\
\hline Claw & 0.34 & 0.26 & 0.35 & 0.32 \\
\hline
\end{tabular}

* from chelifore insertion to tip of 4 th lateral processes.

** across 1st lateral processes.

ment about as wide as long. Second segment slightly shorter and more robust than fourth segment. Third segment curved, approximately $3 / 4$ length of preceding segment. Penultimate segment equal in length to sixth and seventh segments. Terminal segment small, about 3 times as wide as long, and bearing digitiform process terminally. All segments with small setules; segments of illustrated paratype armed as in following formula, $\mathrm{L} / \mathrm{R}: 0 / 0,0 / 0,0 / 0$, $0 / 0,2 / 1,3 / 3,3+\mathrm{II} / 2+\mathrm{II}, 2+\mathrm{II} / 1+\mathrm{II}$ (and 1 setule), $1+$ I/I, II/II; all spines denticulated.

Legs (Figs. 3A-H) long, and heavily spinose. First coxa (see Fig. 1A) with 2 distal spiny tubercles and 2 setae. Second coxa (Fig. 3A) clavate in outline, much wider distally than proximally, bearing 5 small spines, and genital pore situated on hyaline membrane. Third coxa shorter than second, subquadrate, with 7 spines. Femur long, inflated proximally, with numerous spines (21 in Fig. 3A; arrow indicating missing seta) and 2 distolateral spiny tubercles. First tibia slightly longer than femur, with spines (26 in Fig. 3A) and 1 distolateral spiny tubercle. Second tibia about as long as preceding segment, slender, with spines (30 in Fig. 3A; arrow indicating missing seta). Tarsus (Fig. 3E) small, with 3 stout spines on inner margin and 1 small seta on outer distal corner. Propodus curved, with 4 stout heel spines and 6 smaller spines on sole, and 9 slender attenuate spines (arrow indicating missing seta in Fig. 3E). Claw slightly curved, about $7 / 10$ length of propodus; auxiliary claws approximately $3 / 5$ to $3 / 4$ length of claw. Terminal portions of legs 1-4 (Figs. 3B-H) displaying variations not only among the legs, but also within pairs (compare Figs. 3B, C, E, and G, then Figs. $3 C$ and D, 3E and $F$, and $3 G$ and $H$ ).

Male. - Trunk (Fig. 4A) similar to that in female; spiny tubercles on mid-dorsal surface of first-third trunk segments. Lateral processes closer together than in female, and bearing several (3-9) spiny tubercles. Ocular tubercle unornamented. Cephalic horns longer and more curved than in female. Measurements of allotype and male paratype are included in Table $\mathrm{I}$.

Chelifore (Figs. 4B-D) similar to that in female, with varying numbers of spiny tubercles and spines. Chela (Fig. 4D) with 1-2 barbed spines and 2 small, apical, digitiform processes probably representing remnants of fingers.

$\mathrm{Palp}$ as in female, except armature formula as follows, $\mathrm{L} / \mathrm{R}$ : $\quad 0 / 0, \quad 2+\mathrm{I} / 1+\mathrm{I}, \quad 1+\mathrm{I} / 1+\mathrm{I}$, $5+\mathrm{V} / 5+\mathrm{VII}, 11 / 11,11 / 10,6 / 6,7 / ?, 6 / ?$.

Oviger (Figs. 4E, 5A, B) with armature formula, 


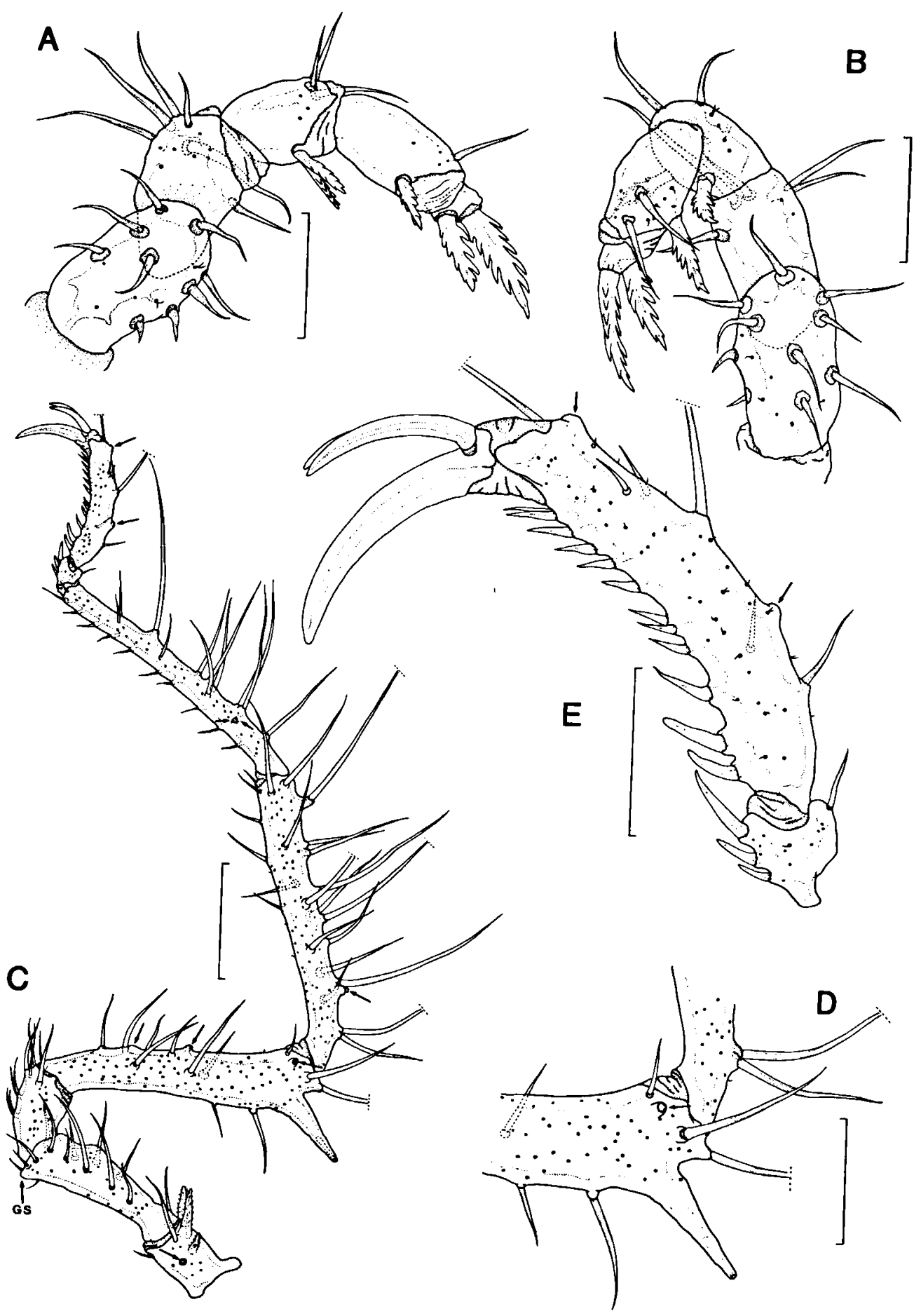

Fig. 5. Ammothella killix n. sp., o paratype: A, terminal segments of right oviger, ventral; B, terminal segments of left oviger, ventral; C, third leg, anterior (GS = genital spur); D, cement gland of third leg, anterior; E, terminal segments of third leg, anterior. Scales: $0.1 \mathrm{~mm}$ in A, B; $0.5 \mathrm{~mm}$ in C; $0.3 \mathrm{~mm}$ in D; $0.2 \mathrm{~mm}$ in E. Small arrows represent missing spines. 
L/R: $0 / 0,3 / 3,1 / 1,7 / 7,8 / 8,9 / 10,6 / 5$, $3+\mathrm{II} / 2+\mathrm{II}, 1+\mathrm{I} / 2+\mathrm{I}, \mathrm{II} / \mathrm{II}$.

Legs (Figs. 5C-E) similar to those in female. Femur with large, distal, conical cement gland. Genital spur (Fig. 5C) a very low protuberance on legs 3 and 4. Number of spines on legs as variable within and among pairs as in female.

Distribution. - The new species is known only from its type-locality, Cortez Ridge, San Nicolas Island, California. Apparently, it is a deep-water species, collected in a single dredge haul between 366 to $372 \mathrm{~m}$ depth.

Etymology. - The specific name killix, a Greek masculine noun for an ox with crooked horns, alludes to the paired spiny tubercles on the cephalic segment; it stands as a masculine noun in apposition to the generic name.

Remarks. - Ammothella killix has a unique combination of characters that are not individually unusual in the genus. The type-species $A$. rugulosa (Verrill, 1900) (= appendiculata (Dohrn, 1881)? [fide Child, 1979, 1982b, and Stock, 1975]) and 24 of the other 33 species currently assigned to $\mathrm{Am}$ mothella lack mid-dorsal ornamentation. The remaining nine species, including $A$. killix, bear tubercles, papillae, long spines, or hollow tubes mid-dorsally.

Of this group, A. thetidis Clark, 1963, known from Australia, is least similar to $A$. killix. It has the ocular tubercle near the middle of the cephalic segment, has auxiliary claws 1.5 times the length of the primaries, and lacks both scape and abdominal tubercles. A second Australian species, $A$. stocki Clark, 1963, also has its ocular tubercle in the middle of the cephalic segment, has paired blunt papillae mid-dorsally on the second trunk segment, separate cephalic and first trunk segments (possibly an artifact), and the fourth palp segment longer than the second. The western Pacific $A$. stauromata Child, 1982 lacks abdominal tubercles, has a much longer proboscis, bears a more robust ocular tubercle, has complete trunk segmentation, and lacks tarsal spines.

The sole non-Pacific member of the group, the
Caribbean A. exornata Stock, 1975, differs from $A$. killix in having the scape segments subequal in the male (Child, 1979: 9) or segment 1 longer in the female, in lacking spiny tubercles distally on the femur and tibia 1 in the female, in having a much larger genital tubercle and shorter cement gland tube in the male, in possessing a cluster of small tubercles around the base of the ocular tubercle, and in having a compact robust body.

The four remaining species, $A$. menziesi Hedgpeth, 1951, A. setosa Hilton, 1942, A. spinifera Cole, 1904, and $A$. tuberculata Cole, 1904, are from California waters. They all differ from $A$. killix in the following characters: shorter second segment of the palp, shorter and more robust ocular tubercle, lack of tubercles on the ocular tubercle and abdomen, partial or complete suture between the third and fourth trunk segments, and clavate second segment of the scape (except perhaps $\boldsymbol{A}$. setosa). The slender, spiny cephalic tubercles and basally fused chelifore scapes also distinguish $A$. killix from other California species.

Anterior cephalic ornamentation in Ammothella is quite variable in size and type, although in a few species (e.g. A. elegantula Stock, 1968) it is completely absent. The anterior cephalic corners are prolonged into spurs in some species (e.g. $A$. dawsoni Child \& Hedgpeth, 1971). When the segment lacks spurs, the anterior cephalic corners may bear multilobed tubercles ( $A$. cymosa Nakamura \& Child, 1983), trifid tubercles ( $A$. exornata Stock, 1975), simple digitiform tubercles ( $A$. menziesi Hedgpeth, 1951), bifid digitiform tubercles ( $A$. rostrata Losina-Losinsky, 1961), serrate tubercles $(A$. marcusi Hedgpeth, 1948), or spines ( $A$. setosa Hilton, 1942). The single spiny tubercles of $A$. killix are a new variation on this theme. Alternatively, the anterior border is rounded and accompanied by low tubercle-like swellings tipped with small papillae above the palp insertions ( $A$. symbia Child, 1979).

The only other unequivocal report of basal chelifore fusion in Ammothella was by Hong \& Kim (1987: 144-145) who described and illustrated fusion in $A$. monotuberculata. The figure of the male holotype of $A$. symbia (Child, 1979: 13) seems to indicate that basal fusion also occurs in this species, but there is no mention of fusion in the description. 
Similarly, the figure of $A$. longioculata in Krapp (1973: Fig. 2) seems to show basal fusion, but the original description neither figures nor refers to the basal chelifore segments (Faraggiana, 1940: 153-154). The character is invariate in A. killix, but its diagnostic value is unclear since it may not have been reliably reported in the past.

Complete detailed descriptions of the appendages, including armature formulae of the palp and the oviger, of the new species were provided in hopes of discovering potentially useful taxonomic characters. However, our studies suggest that the armature formulae for the palp and oviger are not taxonomically useful. The number of setae is variable not only among the specimens, but also between right and left appendages within the same specimen. The same situation holds true for the spination of legs $1-4$.

Little can be deduced of the ecology of the species from the single collection currently known. The dredge haul from which it was removed consisted of fragments of one or more large siliceous sponges. Several of the individuals were grasping spicules with their legs; this may reflect association of the pycnogonid with the sponge, or may be simply the result of the two species being tossed together in the same trawl. Most of the algal and cnidarian substrates normally frequented by shallow-water pycnogonids are absent in the upper slope habitat of $\boldsymbol{A}$. killix. A large, sessile, and relatively abundant invertebrate such as the sponge would potentially provide both refuge and food to the pycnogonid.

\section{Key to adult Ammothella species from California}

1. Legs with both primary and auxiliary claws well developed

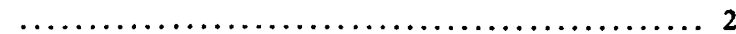

- Primary claw absent or vestigial

A. biunguiculata Dohrn, 1881

2. Second segment of chelifore scape clavate $\ldots \ldots \ldots \ldots 3$

- Second segment of chelifore scape linear .......... 5

3. Ocular tubercle height several times diameter; lateral processes separated by $1 / 4$ their width or more ....... 4

- Ocular tubercle about as wide as tall; lateral processes touching or nearly touching ........A. tuberculata Cole, 1904

4. Single tubercles mid-dorsally $\ldots \ldots \ldots \ldots \ldots \ldots \ldots \ldots$ ................... menziesi Hedgpeth, 1951

- Paired hollow tubes mid-dorsally . A. spinifera Cole, 1904
5. Lateral processes each with single smooth projection; abdomen lacking spines or tubercles ... A. setosa Hilton, 1942

- Lateral processes each with multiple spined tubercles; abdomen with spined tubercles ............ A. killix n. sp.

\section{Acknowledgments}

We thank Mr. Hans Kuck and Dr. Joel Martin, Natural History Museum of Los Angeles County for the loan of the specimens and for providing collection data. We also gratefully acknowledge the Environmental Monitoring Division, Hyperion Treatment Plant, City of Los Angeles, and the Marine Biology Laboratory, Los Angeles County Sanitation Districts for the use of their facilities without which this study could not have been undertaken. We are grateful to Deborah Horn-Bostel for patiently explaining the intricacies of stippling the illustrations and to Ann Martin, EMD, Hyperion Treatment Plant, for help with the literature. Special thanks are extended to Mr. C. Allan Child, Department of Invertebrate Zoology, National Museum of Natural History, Smithsonian Institution, for helpful advice throughout the course of this investigation, and to Mr. C. Allan Child, Dr. Koichiro Nakamura, Japan Women's College of Physical Education, and Dr. Jan H. Stock, Institute of Taxonomic Zoology (Zoological Museum), for critically reviewing the manuscript.

\section{References}

Arnaud, F. \& C.A. Child, 1988. The South African Museum's Meiring Naude cruises, part 17. Pycnogonida. Ann. S. Afr. Mus., 98(6): 121-187.

Child, C.A., 1979. Shallow-water Pycnogonida of the Isthmus of Panama and the coasts of Middle America. Smithson. Contr. Zool., 293: 1-86.

Child, C.A., 1982a. Pycnogonida of the western Pacific islands, I. The Marshall Islands. Proc. biol. Soc. Wash., 95(2): 270-281.

Child, C.A., 1982b. Pycnogonida from Carrie Bow Cay, Belize. In: K. Rutzler \& I.G. Macintyre (eds.), The Atlantic barrier reef ecosystem at Carrie Bow Cay, Belize, 1: Structure and communities. Smithson. Contr. mar. Sci., 12: 355-380.

Child, C.A. \& J.W. Hedgpeth, 1971. Pycnogonida of the Galapagos Islands. J. nat. Hist., 5: 609-634.

Clark, W.C., 1963. Australian Pycnogonida. Rec. Aust. Mus., 26(1): 1-81.

Cole, L.J., 1904. Pycnogonida of the West coast of North America. Harriman Alaska Exped., 10: 249-330.

Dohrn, A., 1881. Die Pantopoden des Golfes von Neapel und der angrenzenden Meeres-Abschnitte. Fauna Flora Golf. Neapel, 3: i-viii, 1-252, pls. I-X, Xa-XVII, [1-10, $10 a-17]$.

Faraggiana, R., 1940. Pantopodi del Mare Ligure. Boll. Musei 
Zool. Anat. comp. R. Univ. Torino, (3) 48(112): 145-158.

Fry, W.G., 1978. A classification within the pycnogonids. In: W.G. Fry (ed.), Sea spiders (Pycnogonida). Zool. J. Linn. Soc., 63(1/2): 197-238.

Fry, W.G. \& J.W. Hedgpeth, 1969. The fauna of the Ross Sea, part 7. Pycnogonida, 1. Colossendeidae, Pycnogonidae, Endeidae, Ammotheidae. Mem. N.Z. Oceanogr. Inst., 49 (= Bull. N.Z. Dep. scient. ind. Res., 198): 1-139.

Hedgpeth, J.W., 1948. The Pycnogonida of the western North Atlantic and the Caribbean. Proc. U.S. natn. Mus., 97(3216): 157-342.

Hedgpeth, J.W., 1949. Report on the Pycnogonida collected by the Albatross in Japanese waters in 1900 and 1906. Proc. U.S. natn. Mus., 98(3231): 233-321.

Hedgpeth, J.W., 1951. Pycnogonids from Dillon Beach and vicinity, California, with descriptions of two new species. Wasmann J. Biol., 9(1): 105-117.

Hilton, W.A., 1942. Pycnogonids from the Pacific. Family Ammotheidae. Pomona J. Entomol. Zool., 34(4): 93-99.

Hong, J.-S. \& I.-H. Kim, 1987. Korean pycnogonids chiefly based on the collections of the Korea Ocean Research and Development Institute. Korean J. syst. Zool., 3(2): 137-164.
Humes, A.G. \& R.U. Gooding, 1964. A method for studying the external anatomy of copepods. Crustaceana, 6: 238-240.

Krapp, F., 1973. Pycnogonids from Pantelleria and Catania, Sicily. Beaufortia, 21(277): 55-73.

Losina-Losinsky, L.K., 1961. [Pantopoda of the far-eastern seas of the USSR]. Issled. Dalnevost. Morei SSSR, Leningrad, 7: 47-117 [in Russian].

Nakamura, K. \& C.A. Child, 1983. Shallow-water Pycnogonida from the Izu Peninsula, Japan. Smithson. Contr. Zool., 386: $1-71$.

Stock, J.H., 1968. Pycnogonida collected by the 'Galathea' and 'Anton Bruun' in the Indian and Pacific Oceans. Vidensk. Meddr. dansk naturh. Foren., 131: 7-65.

Stock, J.H., 1975. Pycnogonida from the continental shelf, slope, and deep sea of the tropical Atlantic and East Pacific. Biological results of the University of Miami deep-sea expeditions, 108. Bull. mar. Sci., 24(4): 957-1092.

Stock, J.H., 1978. Abyssal Pycnogonida from the northeastern Atlantic Basin. Part I. Cah. Biol. mar., 19(2): 189-219.

Received: 20 August 1990

Revised: 17 December 1990 